\title{
SCHOOLING: THE WAY PEOPLE SEE IT
}

\begin{abstract}
In this paper, I discusse how people perceive and give meaning to schooling or education. Based largely on field-data, I organize this discussion on four key themes social status and employment, everyday skills and knowledge, gender and caste, and social relationships. While making these discussions I argue that powerful contradicting forces are operating in educational arena, one, local pressures from below for educational opportunities and improvement and the other, from above, resistance to maintain hierarchy. I show how powerful forces at the local level deny access to schooling to women, low castes and the poor. It is true that the access to schooling to these deprived groups has been improved recently. Nevertheless, the discriminatory forces are still powerful illustrating the tension between the agency of these actors and societal
\end{abstract} structures.
Mahesh Nath Parajuli*

Schooling as a means to reduce poverty and inequality as well as empowering children from deprived communities has long been emphasized (Brown, Halsey, Lauder \& Wells, 1997; UNESCO, 1998). However, conflict theories have defined schooling as an elitist project which tries to implant the legitimised local and national knowledges, values and norms - described as cultural capital - upon those who are subordinated (Dillabough, 2003; Gewirtz \& Cribb, 2003; Jeffrey, Jeffery \&Jeffery, 2005; Robbins, 2005, 2007). Bourdieu saw schooling as a mechanism contributing towards "reproducing the structure of relations between the classes by reproducing the unequal class distribution of cultural capital" (Bourdieu \& Passeron, 1970/1990, p. 188). This presents the schooling as a social stratification process. However, this state project is not without any objection because the social actors are not the passive being. Their agency - a wilful nature of human action, the actors, or their knolwedgeability and capability of doing things (Giddens, 1984, pp. 1-14; Long, 2001) - produce an active contestations against any form of dominations. This makes the school a site where agency and structure are in constant interplay producing contestations and conflicts. An intense process of conflict goes on in and around the school that challenges several societal processes (Levinson \& Holland, 1996; Madsen, 2006).

Setting and the data

Four villages were selected for the present study on a purposive basis. These were Uchchakot and Kalena in Doti, a hill district in the farwestern part of the country and Atrahatti and Mejhi in Nawalparasi, a terai/plain district in the south central part of the country. The purpose behind selecting four villages in two districts was to get more varied pictures of people's understandings of schooling. All four villages presented unique characteristics: Uchchakot was mainly

* School of Education, Kathmandu University 
a village of high caste Bahun with long tradition of teaching and learning; with high illiteracy among its Chhetri and Dalit population Kalena was behind in most socio-economic indicators; Atrahatti was a Tharu settlement - an original ethnic group of the terai; and Mejhi was a mixed settlement of hill migrants.

In 1999, nearly two-third adult literacy (15+) was reported in all four villages except in Kalena where more than four-fifth were illiterate. Again except in Kalena, over 90 per cent primary school-age children were enrolled in school indicating a situation of increased access to schooling in recent years. Income poverty was widespread and subsistence farming, remittance (through mostly labour jobs in India), and daily wages labour were the main sources of livelihood for majority of the poor. Some educated people were also employed in government and other organized sectors.

In all four villages, society was highly stratified along different dimensions - ethnicity, caste and economy being the major ones. These dimensions interplayed with other dimensions like gender to intensify the effects of discrimination and exclusion. That is, Dalits were often the poorest and the most vulnerable and deprived ones. Likewise, women in general were the deprived ones and such vulnerability and deprivation would further intensify in case of Dalit women. New categories of stratification like 'developed' and 'not developed', 'schooled' and 'not schooled', and 'jagire' (employed) and 'not jagire' (not employed) were also found emerging as the outcome of more than 50 years' of development interventions and were interplaying with traditional dimensions (Parajuli, 2002).

Data for the present study were collected mainly in 1999 and 2000. Subsequent field visits were also made in 2004 to have fresh perspectives on people's understandings of schooling. Detailed qualitative interviews with people in the villages

Note: In this paper I have used education and schooling interchangeably and in the sense of schooling.
- parents, students, children out of school, socio-political representatives, social workers, teachers, etc were the main research partners at the local level. They represented different groups - females and males, girls and boys, high and low castes, rich and poor, young and old, 'developed' and 'not developed' and so on. A structured census household survey covering altogether 415 households in all four villages were also conducted as a first phase field-work and with the purpose of understanding those villages as well as for generating key themes. Observations, informal chatting, daily diaries of some children (written on request of the researcher), brief notes/essays of some children (written on request of the researcher) were also important sources of information.

\section{The Meaning of Schooling or Education}

Depending upon the different socioeconomic, political and cultural contexts, people take the meaning of education differently. Educational outcomes are contextualized in the relationship between education, the economy and society (Coffey, 2001, p. 69). However, people in the study villages showed an unconditional faith towards education or schooling. The two women ${ }^{2}$, situated in the periphery and marginalized in many senses, with no opportunity to attend formal schooling and who were forced to face the complexities of a modern system for the first time in their life, took education as a means to face the modern world. The adult mother whose only son was in a hospital bed facing life-threat expressed "all my life it never came to me that I am uneducated but now I am having such feeling. I think, I learn nothing in my whole life." The young woman whose husband was dying in a hospital bed once expressed "had I gone to school when I was a child, I could be of some help now to my husband. But my father didn't send me to the school and I didn't know that I should go to the school." It was clear that in the time of trouble, they were having a feeling of helplessness and, as a resort, their mind was 
diverted towards the need for and importance of education.

A small girl Kalpana (grade 8, age 14) see lack of education as the reason for all sorts of problems women were facing in her world. She expressed her trust on education by writing "I have to study hard. Otherwise, my life would be like my mother's. If I do not labour well now, I cannot become a thulo ra asal manchhe (great, important and good person) as my mother dreams for me. I won't be like my mother." The case was same with almost all respondents in all four villages. They have expressed, with education one would be able to 'improve one's situation', 'open her/ his eyes and ears', 'save oneself from oppression', 'come out of oppression' and so on. All these imply that people regard education as a step towards the empowerment process eventually leading for better life.

In the following four subsections I have discussed and analysed how people see the meaning of education based on their expectations on the outcomes of schooling. These discussions and analyses are based upon as they narrated me their real life stories of aspirations, of struggles, and of successes and failures and are the products of interactions between myself and my research partners.

\section{Social Status, Employment and Schooling}

People in the study villages took the meaning of schooling in different ways linking it with a number of socioeconomic outcomes such as awareness, social status and employment. "You will be a learned person and people will respect you" or "if my daughter were educated that would have brought respect to me also", etc. were some examples of people's expression. I have observed that people consult with an educated person on various matters of intra-local relations like further study of son/daughter, going to bank for opening an account, discussion on development related matters like repairing the village road or drinking water supply system, accompanying with other villagers to go to some government office, etc. Such consultations with educated people were made because they were regarded as informative, and aware of the facts or rules and regulations. Information and awareness were thus seen as important outcomes of education. In the words of Kalyani Kumari Singh (female, 39, Tharu, NFE ), "educated people can read and thus will have the information about issues, people and places. That will make them able to differentiate what are good and what are bad." Many Tharus and Dalits were of opinion that their undeveloped situation was due to their lack of awareness about their own pitiable situation. But now, according to them, education was making them aware of their realities and they were hopeful that it would bring positive changes in their social situation.

People have also expressed education as an asset - a source of power that defends against all sorts of oppression and helps people to come out of oppression. Comments made by Bishnu Sharan Chaudhari $^{1}$ (male, 34 years, Tharu, higher education) make these points clear:

Education is an asset for a person. Through this asset one can get employment and one becomes smart, capable and knowledgeable to face the world. Education is the power. Utilizing this power, educated people can make their life easier and as desirable. ... Educated person can defend themselves against all sorts of cheating and oppression. Similarly, education helps people to come out of oppression, because with education, they can evaluate and improve their situations.

1 The two women were mother and wife of Bishnu, a teacher in Atrahatti. While this study was going on Bishnu suffered serious health problem and was brought and admitted in a hospital in Kathmandu. His mother and wife were with him while he was in hospital. Largely illiterate, unable to understand and speak Nepali, and first time out from their village and nearby areas both women found themselves highly confused and unable to cope with the hospital system. 
Employment and income or opportunities for better earning, were commonly reported as important economic outcomes of education. People have expressed their opinions saying, 'We have invested in education lots of time and money so it is natural that we do expect some return from it.' Most commonly expressed return was jagir (salaried employment in some organized agencies, most preferably in the government service). People were alike in expressing employment as an educational outcome, be they in Doti or Nawalparasi, female or male, rich or poor or high caste or low.

This high economic emphasis to education was due to great materialistic successes of some educated people enjoying privileges, earnings and power in the modern world of Kathmandu or some other cities. So, parental investment in their children's education can be explained as a strategy for social and economic status attainment, being away from the village, and securing the better and safe future for themselves and for their children. Education was thus widely perceived by members of socially or economically disadvantaged groups as the most promising chance of upward mobility for their children (Dreze \& Sen, 1995, p. 110).

Not only parents but the children also gave priority to earning through some sort of nonagricultural occupation - job, teacher, nurse, shop-owner, mechanic, etc. The words of Paltu Tharu, a 15 years old eighth grader boy illustrate his strong desire for earning, "In future, I would like to go to politics because my teacher had told me that these days politicians make lots of money."

Schooling was thus expected to result in a number of interlinked aspects like nonagricultural and non-manual employment, income, enhanced socio-economic status, information and awareness and thus respect in the society. Similarly, schooling was also associated with an opportunity to migrate from the village, a synonym for superstition, poverty, underdevelopment and thus the 'problem', to urban areas which were synonym for modernity, development, prosperity in the state development discourse (Pigg, 1992, 1993).

\section{Everyday skills or knowledge and schooling}

Respondents have mentioned several other reasons for schooling that would bring direct influence in their practical day-to-day life. These reasons, however, were linked to the social status or respect one can have by mastering these everyday skills or knowledge. 'Can speak in front of others', 'clarity in speech and presentation', 'speak and understand Nepali', etc. were some important oratory benefits of education as mentioned by the people. Similarly, being capable to read signboards, bus numbers, pamphlets, wrappers, identifying bank notes, etc. were some comprehending benefits of education. Making signature and thus avoiding the need for lyapche (thumb print) and being able to do calculations were also substantial outcomes of education. Actually, these benefits were powerful and would bring a substantial change in the life of the people. Being able to speak in front of others was the quality that would have important impact on uplifting the people's self-esteem in a society where long tradition of oppression and injustice prevailed. According to Kunti (female, 28 years, Tharu, SLC) 'As I have studied to some extent, I don't feel any fear while speaking with others. I know there is no reason for which I should fear.' She also added that shopkeepers could not cheat her because they knew she was literate and could not be deceived.

For many people, being able to write or sign their name was powerful in many senses. This capability was, as if re-identifying oneself, a sense of pride and high self-esteem. Until some years ago people had little need to interact with other institute or agency outside the village and thus there was no need to be literate. Lately, new and modern agencies like cooperatives, banks, service agencies, health centres, media centres, etc. were evolving and people had to deal with them. As such, it was necessary that people 
prepare themselves with necessary skills so that they could avail themselves with the services and opportunities offered by those agencies. People have understood that they could not benefit themselves from those services and opportunities if they were not empowered with literary skill. Again, to quote Kunti Devi Chaudhari:

One of the main reasons they want to learn, read and write is to become able to say that I can read and write. They are very much enthusiastic to become able to write their name. While attending some meetings, they want to show that they are literate people. Whenever they go to some offices for some business and if they have to write their names or make their signatures they don't like to say 'I can't sign my name.'

Different everyday skills were thus important and often only educational outcomes for large majority of deprived children. These skills would greatly contribute to enhance the social status of a person. Writing skill was of great value not only to recreate oneself but also to create one's space in the family and in the society. Even the skill to sign one's own name was enough to reinvent oneself.

\section{Gender, Caste and Schooling}

Gender and schooling were very closely associated phenomena in the study villages. Though the situation was improving in favour of their schooling, they have to show a very strong commitment and interest towards education in order to achieve some success. The reason was basically the patriarchal values of the society which do not give importance to women's education. At the more practical level two factors restrict girls' access to schooling: one, parents' worry about their daughter's marriage and the other, traditional role given to women that do not expect any substantial economic support from them. Some respondents have mentioned that many parents see different educational outcomes for sons and daughters. Most important educational outcome for the daughter was better marriage. That is, parents send their daughters to school so that they could find better groom later on and prepare them as a better wife. The following words of Hari Prasad Pujara (male, 66 years, Bahun, higher education) illustrate these realities.

A daughter has to do more work in the house and farm because parents see this as training to her. After all, after the marriage she has to do all these things. She would be able to do these well if she is trained while in maternal home. Regarding girls' education, many people take it as training to her so that she can have a better husband and be able to satisfy the husband's family by being able to perform her duties in a better way.

Kunti (female, 28 years, Tharu, SLC) has explained how such discriminations were internalised in the society and taken as normal, "It is taken as normal while sons play or study, daughters remain busy in household works. Daughters do not complain because they are told from the very childhood that it is the tradition and it is normal." The issue of gender discrimination in schooling was thus closely related with existing cultural practices that remind women only of their responsibilities but fail to see them as independent beings and their rights.

How such discrimination is normalized was illustrated by the case of Geeta and Uma, two graduate course girl students of Bahun caste. I had interacted with them together. They were of opinion that they were not in a position to oppose any decision made by the male members of the household even if they do not like those decisions. They added, "Somewhere in mind, there is a feeling that being girl, we should not go against our fathers and should obey them; this is discipline and this is being good. We can do nothing against social tradition of this place." 
This can be an example of cultural reproduction and illustrates the implicit objective of education - domesticating and subjugating, rather than liberating or allowing being critical. This raises the fundamental question about the objectives of education as planned and implemented by the state - how far an education system can contribute towards bringing social change (Coffey, 2001, p. 73).

However, people took the schooling as an important social force that was bringing change in social practices. Many were of opinion that as more and more girls were attending the school, old relationships were changing. Along with schooling some other aspects like women's participation in some group like mothers' club, users' group, youth club were also contributing towards bringing such change. Some people have begun to see women as change agents in the society. To quote Bimal Dutta Panta (male, 56, Bahun, higher education), "Perhaps women will bring the change. They are coming forward and are challenging many of our traditional thinking. When you have educated daughters or daughterin-laws in your home you cannot ignore their presence. They are no more obedient women only. Nowadays they argue." However, as I have observed in my study villages very few women were fortunate enough to make their presence noticeable. In Kalena, no girl had completed the primary education (grades 1-5) and in Atrahatti, only two women had SLC. What is important is that people see schooling as one of the key factors responsible for societal change.

Ethnicity or caste was an important dimension of schooling in the study villages. High ethnic disparity in terms of literacy and schooling were noted in those villages. Paruli Sarki, a farmer and an occasional daily labourer, (female, 46 years, Dalit, NFE) explains why her daughter (15 years old at the time of interview) dropped out from the school while at grade two,

During that time, people used to say that a Dalit girl did not need to go to school. At that time, there was heavy workload on me at home and on the farm because her father was in India and I was alone with two small children (son and daughter). So, I decided to pull her from the school, though she was willing to continue, and let the son continue his schooling. But now I regret that day. If she were educated, she could earn money and bring respect to all of us.

Paruli's daughter had to face discrimination from three sides - by being a daughter, by being a Dalit and by being a poor. At that time, pulling out her daughter from the school was a necessary strategy for Paruli.

Ganga Damai, 17 years old tailor-woman, had to dropout from school two years ago while studying at grade five in order to marry. After two years she was feeling that if she had opportunity to continue her study she might be getting some job in future. According to her, despite her willingness to continue schooling her father forced her to marry. For her father marrying her was more important than her schooling. She wanted an escape from her Dalit status and schooling was her only hope. But the marriage shattered all her hopes.

Thus, schooling was closely linked with gender and caste. Cultural practices rather than the economic status of the family determine the schooling of the girls (see, Colclough, Rose \& Tembon, 2000; Stephens, 2000). The combined effect of these multiple barriers denies access to schooling to women, Dalits and the poor. Despite these realities, these hitherto oppressed groups have expressed unconditional faith towards schooling as the only available strategy to raise their status in the society. However, as noted by some of the respondents, improvements in such societal practices were experienced. The presence of women, their agency, was now increasingly being felt in the family as well as in the society. A tension was nevertheless going 
on between powerful structural forces and the agency of these deprived groups of the people. People think schooling has important positive role in this process.

\section{Social Relationships and Schooling}

While in study villages, I observed that when some people were asked about the age of their son or daughter they generally replied by saying 's/he is now grown up and studies in this or that grade'. This showed that schooling was becoming an important element in framing social relationships and identity. It was also found that some particular aspects of social relationships were greatly influenced by schooling. These included generational tension, diffusion of authority, and relaxation on caste relationships.

Responses made by some of my respondents indicated generational tension between older people and youths. Older people see lack of discipline and respect among youths. To quote Ram Janam Chaudhari (male, 64, Tharu, literate):

Today's youth, particularly those who attend school, are very much irresponsible and careless people. Neither do they have discipline nor do they respect the elder people. They do not show any interest in our culture and traditions. I do not see they are interested in study also. Neither do they work in the field nor do they have any other occupation. They just listen to music on radio and see cinema and pass their time.

In the definition of older people, these youths were leading a life of fragmented identity. But from the perspectives of youths, they might be seen as reflecting their own critical evaluation of societal structures. This gives them the agency that rejects and contests against structures of schooling and societal practices (Skinner \& Holland, 1996; King, 2005).
A second example of generational tension was related with women's agency and empowerment. Some elderly people disliked schooled women who go against societal practices. Kunti (female, 28 years, Tharu, SLC) was an example of such dislike. She was forced to discontinue her schooling due to her marriage while at grade nine. When she decided to continue again she was greatly opposed by her family on the ground that married women did not go school. She, however, continued and did the SLC. When she decided to work as social worker, under a local NGO, she had to face harassment from her family. According to her, "those days were most difficult days of my life. I had to face even the physical harassment and charges of bad characters. However, I continued and now I do not have to face such oppositions." Nevertheless, tension was there.

Diffusion of authority was one of the important outcomes of schooling and was found more pronounced at the family level. Earlier, when the household decisions were at the hands of household heads, there were little chances of dialogue and influencing the decision-making for other family members. Ram Janam Chaudhari (male, 64, Tharu, literate) recalled his days when his father rejected his idea of running a shop in the village without even evaluating his proposal. He said, "Now, I even do not know what my son is doing." While Ram Janam expressed his dislike, Bimal Dutta Panta (male, 56, Bahun, higher education) had learnt to adjust over the situation. He noted: "I am getting older and my sons are acquiring important positions in the society due to their education and coming of age. My daughter-in-laws are also educated. I cannot ignore what they think. Earlier I would make my decisions first and then consult with my sons. Now, I first consult with them and then make my decisions." The difference was thus clear between two times and the role of schooling in bringing such changes was important. 
The same thing was true about gradual relaxation on caste relationships. Some people have accorded schooling behind such changes and was largely the outcome of increasing Dalit participation in schooling though some other factors like exposure to media, increasing contact with the outer worlds, etc. were also there. The behavioural change among youths was particularly clear both among high and low castes. According to Jetha Damai (male, 42 years, Dalit, grade five), "There has been great improvement in the situation of caste based discriminations in recent years" and he sees education behind such change.

Kamal Damai, a Dalit youth, has noted, "Nowadays many Dalits are getting education and are being aware of the social reality and their rights." He also noted that high caste people were also changing themselves realizing that the days were now not like the bygone days. According to him, "if one is smart, educated, and has own independent source of livelihood then one is free, at personal level, from exclusion." Kalu Nagari, a Dalit youth, did not continue his schooling after grade seven, "I realized that I cannot achieve any thing by staying at school and thus left the school. However, that much of education proved important for me because with that I got an opportunity to work with an NGO in Silgadhi and got an opportunity to travel many places." According to him people in the village behave towards him differently unlike to any other Dalits because he was 'educated and earning well' to support his family. The cases of these two youths Illustrate that though they had to dropout of school early because of differences in cultural capital they hold and the cultural capital of school, their initial schooling provided an impetus for what they achieved in their life afterwards.

\section{Conclusion}

For the people in the study villages, employment and upward mobility in social status were two most important meanings of schooling. These meanings were closely related with the desired migration from the village to urban areas. A life away from agricultural fields, hard labour, and risk of production or market failure but toward a perceived life of high status, salaried, no manual labour, and little risk. That is, people wanted to disassociate themselves from village, from 'ignorance', from 'underdevelopment', and from 'poverty' and want to see themselves associated with urban areas, with some office job, with 'knowledge', with 'development', and with 'prosperity'. People expected schooling as a means to achieve all these. Such perception was an obvious outcome of development and modernization programme carried out since more than five decades.

Schooling, however, was also linked with many other everyday skills and facilities like an access to a number of social, economic and political services and facilities. Similarly, it was also linked with aspects like information, awareness, and more importantly with a process of developing a new self and identity, a re-invention of oneself, and creating a new space in family and village social life. Many people also perceived schooling as an important social force in bringing change against different structural forces that were active against facilitating access to people of oppressed groups like women, Dalits and poor. Unlike the presence of such forces, people have remarked that the agency of these people have been active recently in making their presence noticeable. Nevertheless, a tension was going on between the agency of women, Dalits and the poor and powerful oppressive structural forces. Similar tensions were observed in some areas of social relationships like generational, gender and caste relationships. The role of schooling was noted in all these instances implying that schooling was becoming an important element in framing social relationships.

Though people were active towards schooling, the relationship between the school and the society was centrally controlled as a result of centrally organized school system and hierarchical 
social structure. Thus, it can be derived that there is a pressure from below for educational opportunities, change and improvement but contradicting such local forces; there is resistance from above to maintain hierarchy.

Analytically, schooling is linked beyond the simple equation of social mobility. The meanings of schooling experiences are much more complex and multifaceted (Coffey, 2001, p. 68) and is often linked with dual and contradictory process of cultural reproduction and cultural production (see, Bourdieu \& Passeron, 1970/1990; Levinson \& Holland, 1996). Cultural reproduction is maintaining, through the process of schooling, the existing societal hierarchy and structure, as in case of Geeta and Uma. Patriarchal structural forces of the society had subjugated them and they have internalised the domination. Cultural production, on the other hand, argues for the agency in the actor that contest and reject those structures. However, reproduction and production are not to be understood as discrete and opposite processes (Gewirtz \& Cribb, 2003). These are often enacted on a concurrent and processual basis and are received differently depending upon the time and context. Actors experiencing and participating in reproduction process might be experiencing and participating in production process at some other time and context or even at the same time and context.

Actors like Geeta and Uma were dominated by reproduction process but Kamal, Kalu and Kunti contested with the structural forces and struggled their own way either by rejecting the schooling or by challenging the schooling and societal structure staying within it. Amidst dissolution of traditional narratives, social actors like Kamal, Kalu and Kunti were in the process of struggling for their own space and identity deriving their own agency as well as reflexivity from the project of modernization (see, Bauman, 2004). Struggling in and around schooling they were thus contributing towards creating new meanings and directions not only for themselves but for the whole society. Notwithstanding, tensions and dilemmas were always there as the outcome of socio-cultural, political and historical contexts people were living in.

\section{References}

Baumann, Z. (2004). Identity: Conversations with Benedetto Vecchi. Cambridge: Polity Press.

Bourdieu, P. \& Passeron, J. C. (1990). Reproduction in education, society and culture ( $2^{\text {nd }} \mathrm{Ed}$.) (R. Nice, Trans.). London: Sage Publications. (Original work published 1970)

Brown, P., Halsey, A. H., Lauder, H, \& Wells, A. S. (1997). The transformation of education and society: An introduction. In A. H. Halsey, H. Lauder, P. Brown \& A. S. Wells (Eds.), Education: Culture, economy, society (pp. 1-44). Oxford: Oxford University Press.

Coffey, A. (2001). Education and social change. Buckingham: Open University Press.

Colclough, C., Rose, P. \& Tembon, M. (2000). Gender inequalities in primary schooling: The roles of poverty and adverse cultural practice. International Journal of Educational Development, 20(1), 5-27.

Dillabough, J. A. (2003). Gender, education and society: The limits and possibilities of feminist reproduction theory. Sociology of Education, 76, 376-379.

Dreze, J. \& Sen, A. (1995). India: Economic development and social opportunity. New Delhi: Oxford University Press.

Gewirtz, S. \& Cribb, A. (2003). Recent readings of social reproduction: Four fundamental problematics. International Studies in Sociology of Education, 13(3), 243-260.

Giddens, A. (1984). The constitution of society. Cambridge: Polity Press.

Jeffrey, C., Jeffery, P. \& Jeffery, R. (2005). Reproducing difference?: Schooling, jobs, and empowerment in Uttar Pradesh, India. World Development, 33(12), 2085-2101.

King, A. (2005). Structure and agency. In A. Harrington (Ed.), Modern social theory: An introduction (pp. 215-232). New York: Oxford University Press.

Levinson, B. A. \& Holland, D. (1996). The cultural production of the educated person: An introduction. In B. A. Levinson, D. E. Foley and D.C. Holland (Eds.), The cultural production of the educated person: Critical ethnographies of 
schooling and local practice (pp. 1-54). New York: State University of New York Press.

Long, N. (2001). Development sociology: Actor perspective. London: Routledge.

Madsen, U. A. (2006). Imagining selves: School narratives from girls in Eritrea, Nepal and Denmark: Ethnographic comparisons of globalization and schooling. Young, 14(3), 219-232.

Parajuli, M. N. (2002). The state, the school and the society: Dilemmas and crises in education in Nepal. Unpublished doctoral dissertation, The Danish University of Education, Copenhagen.

Pigg, S. L. (1992). Inventing social categories through place: Social representations and development in Nepal. Comparative Studies in Society and History, 34(3), 491-513.

Pigg, S. L. (1993). Unintended consequences: The ideological impact of development in Nepal. South Asia Bulletin, 13(1\&2), 45-58.
Robbins, D. (2005). The origins, early development and status of Bourdieu's concept of 'cultural capital'. The British Journal of Sociology, 56(1). 13-30.

Robbins, D. (2007). Sociology as reflexive science: On Bourdieu's project. Theory, Culture and Society, 24(5), 77-98.

Skinner, D. \& Holland, D. (1996). Schools and the cultural production of the educated person in a Nepalese hill community. In B. A. Levinson, D. E. Foley \& D. C. Holland (Eds.), The cultural production of the educated person: Critical ethnographies of schooling and local practice (pp. 273-299). New York: State University of New York Press.

Stephens, D. (2000). Girls and basic education in Ghana: A cultural enquiry. International Journal of Educational Development, 20(1), 29-47.

UNESCO. (1998). Basic education for empowerment of the poor. Bangkok: Author. 